\title{
Nomograms for predicting survival outcomes in patients with primary tracheal tumors: a large population-based analysis
}

This article was published in the following Dove Press journal:

Cancer Management and Research

\author{
Junmiao Wen ${ }^{1,2, *}$ \\ Di Liu',2,* \\ Xinyan $\mathrm{Xu}^{1,2}$ \\ Donglai Chen ${ }^{3}$ \\ Yongbing Chen ${ }^{4}$ \\ Liang Sun ${ }^{5}$ \\ Jiayan Chen ${ }^{1,2}$ \\ Min Fan ${ }^{1,2}$
}

'Department of Radiation Oncology, Fudan University Shanghai Cancer Center, Shanghai 200032, People's Republic of China; ${ }^{2}$ Department of Oncology, Shanghai Medical College, Fudan University, Shanghai 200032, People's Republic of China; ${ }^{3}$ Department of Thoracic Surgery, Shanghai Pulmonary Hospital, Tongji University School of Medicine, Shanghai 200433, People's Republic of China; ${ }^{4}$ Department of Thoracic Surgery, The Second Affiliated Hospital of Soochow University, Medical College of Soochow University, Suzhou 215000, People's Republic of China; ${ }^{5} \mathrm{School}$ of Radiation Medicine and Protection, Medical College of Soochow University, Suzhou 215I23, People's Republic of China

*These authors contributed equally to this work
Correspondence: Jiayan Chen Department of Radiation Oncology, Fudan University Shanghai Cancer Center, No. 270 Dongan Road, Shanghai 200032, China

Tel/Fax +86 2I 64I75590

Email chenjiayan@fudan.edu.cn
Background: The aim of this study was to develop and validate reliable nomograms to predict individual overall survival (OS) and cancer-specific survival (CSS) for patients with primary tracheal tumors and further estimate the role of postoperative radiotherapy (PORT) for these entities. Patients and methods: A total of 405 eligible patients diagnosed between 1988 and 2015 were selected from the Surveillance, Epidemiology, and End Results database. All of them were randomly divided into training $(n=303)$ and validation $(n=102)$ sets. For the purpose of establishing nomograms, the Akaike information criterion was employed to select significant prognostic factors in multivariate Cox regression models. Both internal and external validations of the nomograms were evaluated by Harrell's concordance index (C-index) and calibration plots. Propensity score matching (PSM) method was performed to reduce the influence of selection bias between the PORT group and the non-PORT group.

Results: Two nomograms shared common variables including age at diagnosis, histology, $\mathrm{N}$ and $\mathrm{M}$ stages, tumor size, and treatment types, while gender was only incorporated in the CSS nomogram. The C-indices of OS and CSS nomograms were 0.817 and 0.813 , displaying considerable predictive accuracy. The calibration curves indicated consistency between the nomograms and the actual observations. When the nomograms were applied to the validation set, the results remained reconcilable. Moreover, the nomograms showed superiority over the Bhattacharyya's staging system with regard to the C-indices. After PSM, PORT was not associated with significantly better OS or CSS. Only squamous cell carcinoma (SCC) patients in the PORT group had improved OS compared to non-PORT group.

Conclusion: The first two nomograms for predicting survival in patients with primary tracheal tumors were proposed in the present study. PORT seems to improve the prognosis of SCC patients, which needs further exploration.

Keywords: nomogram, primary tracheal tumors, overall survival, cancer-specific survival, propensity score matching analysis

\section{Introduction}

Primary tracheal tumor, a rare disease, represents $0.5 \%$ of all malignancies. ${ }^{1}$ Several reports have estimated an incidence of $\sim 0.9$ new cases per 1,000,000 persons per year. ${ }^{2,3}$ Major histological subtypes include squamous cell carcinoma (SCC) and adenoid cystic carcinoma (ACC). ${ }^{4} \mathrm{SCC}$ was reported to be associated with men and smokers, ${ }^{5}$ while nonsmokers were more likely to suffer from ACC. ${ }^{6}$ Patients with tracheal tumors generally present symptoms such as cough and dyspnea. However, these signs are nonspecific, and most patients are misdiagnosed until advanced disease is detected through radiography or bronchoscopy. ${ }^{7}$ Although radical surgical resection 
with negative margins has been suggested to be the optimal option for primary tracheal tumors, the resection rate is remarkably heterogeneous, and the five-year overall survival (OS) among these patients varies from $47 \%$ to $79 \%$ based on previous studies. ${ }^{8-10}$ However, treatment failure attributed to local recurrence and distant metastasis is not rare. According to several retrospective reports, patients with tracheal tumors appear to benefit from adjuvant therapy, ${ }^{11,12}$ but the roles of postoperative radiotherapy (PORT) and chemotherapy remain controversial. ${ }^{13-15}$ Moreover, considering the notably low incidence, there is no widely accepted staging system with sufficient predictive prognostic value for these neoplasms. Thus, the evaluation of tracheal tumors is neither accurate nor convenient for clinicians.

The current literature has shown the precise predictive value of nomograms in the management of other tumors, and they have been broadly implemented in clinical practice. ${ }^{16-18}$ In this study, we aimed to build a nomogram for patients diagnosed with primary tracheal tumors by using the data extracted from the Surveillance, Epidemiology, and End Results (SEER) database and further investigate the prognostic value of PORT by applying a propensity score matching (PSM) method.

\section{Materials and methods}

\section{Selection of study cohort}

We conducted this retrospective study using data retrieved from the SEER database (1973-2015), supported by the National Cancer Institute, which provides information regarding cancer patients in 18 registries of the US covering $\sim 28 \%$ of the US population. ${ }^{19}$ We identified the primary tracheal tumors according to the primary site code C33.9, and the search was limited to the period from 1988 to 2015 (information on tumor size, nodal status, metastatic sites, and extent of disease were not collected in the database until 1988). Only patients who met the following criteria were included: 1) age above 18 years; 2) trachea as the first primary site; 3 ) survival time $\geq 1$ month; and 4) cases with inadequate tumor data (tumor extension, lymph node status, and metastasis). Those with a death certificate or autopsy were excluded. A total of 405 eligible cases were identified and constituted the primary cohort of our study. To develop and validate the nomograms, the primary cohort was randomized into a training cohort $(n=303)$ and validation cohort $(n=102)$.

\section{Definition of tumor data}

Considering that there is no American Joint Committee on Cancer (AJCC) TNM staging system for tracheal tumors, we utilized the tumor features from the SEER database and categorized the patients according to the following classification: 1) Extension status: Extension 1 (E1), invasive tumor confined to trachea; E2, involving adjacent connective tissues (arch of aorta, azygos vein, right brachiocephalic vein, carotid sheath, common carotid artery, jugular arch, phrenic nerves, pretracheal fascia, recurrent laryngeal nerve, subclavian artery, and vagus nerve) or adjacent organs/structures (cricoid cartilage, esophagus, pleura, not otherwise specified: parietal and visceral; right and left main bronchi, sternum, thymus, thyroid gland, and vertebral column); E3, further contiguous extension; 2) Lymph node status: N0, no regional lymph node involved; N1, regional lymph nodes involved (mediastinal, paratracheal, and pretracheal); and 3) Metastatic status: M0, no metastatic site involved; M1, distant lymph node(s) only, organ metastasis other than distant lymph node(s), or distant metastasis plus distant lymph node(s). To properly estimate the prognostic value of tumor size in patients with tracheal tumor, the tumor size was stratified into two categories (cutoff point $3.9 \mathrm{~cm}$ ) by using the X-tile program (version 3.6.1), which is a practical tool assisting marker cut point analysis according to the minimal $P$-value.

\section{Data collection}

Data extracted for each case included demographics (age at diagnosis, gender, race, marital status, and Contract Health Service Delivery Areas [CHSDA] region), tumor characteristics (as mentioned above), primary tumor treatment (surgery or radiation therapy), months of survival, cause-specific death classification, and vital status.

\section{Statistical analysis}

We employed Student's t-test for continuous data. Categorical variables were evaluated using the chi-squared test or Fisher's exact test. We used the OS (the interval from the date of initial anticancer treatment until the date of death or the last day of follow-up) and cancer-specific survival (CSS) (the time from the data of initial treatment until death from tracheal tumor) as the primary endpoints for comparison. Kaplan-Meier analysis and log-rank test were used for survival analysis. Univariate and multivariate survival analyses were conducted using the Cox proportional hazards model. Nomograms were constructed based on the significant prognostic factors of the multivariate Cox regression analyses. We used the backward step-down process based on Akaike information criterion (AIC) to finally recruit independent prognostic factors into the formulations of the nomograms. Both internal and external validations of the nomograms were conducted based on the training cohort and validation cohort. Calibration curves 
of our nomograms were employed to determine whether the predicted survival and observed survival were in agreement, and the curves were corroborated with 1,000 resamples conducted for validation. We further assessed the performances of nomograms and a staging system proposed by Bhattacharyya ${ }^{20}$ by using the Harrell's concordance index (C-index) ${ }^{21}{ }^{21}$ The $\mathrm{C}$-index ranges from 0.5 to 1.0 , and a larger $\mathrm{C}$-index shows better accuracy for predicting the prognosis. ${ }^{22}$ The comparison between the nomogram and the Bhattacharyya's staging system was performed with the rcorrp.cens function in the Hmisc package in $\mathrm{R} .{ }^{23}$ Recognizing that selection bias may influence the comparison of survival outcomes between patients who did or did not receive PORT, similar with previous study, ${ }^{24}$ a PSM analysis was conducted to reduce the potential differences among baseline characteristics between the two groups. The patients were matched on the basis of a greedy nearest neighbor algorithm with the caliper set at 0.1 . The matching fixed ratio was 1:1. All statistical analyses were processed with $\mathrm{R}$ software version 3.4.2 (Institute for Statistics and Mathematics, Vienna, Austria; https://www.r-project.org/), and a two-side $P$-value $<0.05$ was considered to be statistically significant.

\section{Results}

\section{Patient baseline characteristics}

A total of 405 patients were identified with primary tracheal tumors, and the demographics and characteristics of the training cohort (303 patients) and validation cohort (102 patients) are detailed in Table 1 . The majority of patients in both sets were of white ethnicity, male, married, and from the Pacific Coast and East regions. The most common histological

Table I Clinicopathological characteristics of primary tracheal patients in training and validation cohorts

\begin{tabular}{|c|c|c|c|c|}
\hline \multicolumn{2}{|l|}{ Characteristic } & \multirow{2}{*}{$\begin{array}{l}\text { Training cohort } \\
(n=303)\end{array}$} & \multirow{2}{*}{$\begin{array}{l}\text { Validation cohort } \\
(\mathrm{n}=\mid \mathbf{0 2})\end{array}$} & \multirow{2}{*}{$\begin{array}{l}P \text {-value } \\
0.987\end{array}$} \\
\hline Race (\%) & Black & & & \\
\hline & Others & $31(10.2)$ & $11(10.8)$ & \\
\hline & White & $236(77.9)$ & 79 (77.5) & \\
\hline \multirow[t]{2}{*}{$\operatorname{Sex}(\%)$} & Female & $134(44.2)$ & $46(45.1)$ & 0.969 \\
\hline & Male & $169(55.8)$ & $56(54.9)$ & \\
\hline \multirow[t]{3}{*}{ Year of diagnosis (\%) } & $1988-1999$ & $59(19.5)$ & $18(17.6)$ & 0.801 \\
\hline & $2000-2009$ & 149 (49.2) & $54(52.9)$ & \\
\hline & $2010-2015$ & $95(31.4)$ & $30(29.4)$ & \\
\hline \multirow[t]{4}{*}{ CHSDA region (\%) } & East & $106(35.0)$ & $36(35.3)$ & 0.397 \\
\hline & $\mathrm{NP}$ & $43(14.2)$ & $19(18.6)$ & \\
\hline & $\mathrm{PC}$ & $136(44.9)$ & $38(37.3)$ & \\
\hline & SW & $18(5.9)$ & $9(8.8)$ & \\
\hline \multirow[t]{3}{*}{ Histology (\%) } & $A C C$ & $78(25.7)$ & $31(30.4)$ & 0.190 \\
\hline & Others ${ }^{\mathrm{a}}$ & $96(31.7)$ & $38(37.3)$ & \\
\hline & SCC & $129(42.6)$ & $33(32.4)$ & \\
\hline \multirow[t]{4}{*}{ Treatment (\%) } & None & $33(10.9)$ & $6(5.9)$ & 0.118 \\
\hline & $\mathrm{RT}+$ surgery $^{\mathrm{b}}$ & $113(37.3)$ & $39(38.2)$ & \\
\hline & RT only & $102(33.7)$ & $29(28.4)$ & \\
\hline & Surgery only & $55(18.2)$ & $28(27.5)$ & \\
\hline \multirow[t]{3}{*}{ E stage (\%) } & EI & $155(5 \mid .2)$ & $59(57.8)$ & 0.339 \\
\hline & E2 & $140(46.2)$ & $39(38.2)$ & \\
\hline & E3 & $8(2.6)$ & $4(3.9)$ & \\
\hline \multirow[t]{2}{*}{$\mathrm{N}$ stage (\%) } & No & $214(70.6)$ & $80(78.4)$ & 0.161 \\
\hline & $\mathrm{NI}$ & $89(29.4)$ & $22(21.6)$ & \\
\hline \multirow[t]{2}{*}{ M stage (\%) } & Mo & $268(88.4)$ & $94(92.2)$ & 0.387 \\
\hline & MI & $35(11.6)$ & $8(7.8)$ & \\
\hline \multirow[t]{3}{*}{ Tumor size (\%) } & $\leq 3.9 \mathrm{~cm}$ & $158(72.1)$ & $51(72.9)$ & 1.000 \\
\hline & $>3.9 \mathrm{~cm}$ & $61(27.9)$ & $19(27.1)$ & \\
\hline & Unknown & 84 & 32 & \\
\hline \multirow[t]{3}{*}{ Marital status (\%) } & No & I 30 (44.7) & $43(44.8)$ & 1.000 \\
\hline & Yes & $161(55.3)$ & $53(55.2)$ & \\
\hline & Unknown & 12 & 6 & \\
\hline Age (mean (SD)) & & $59.58(15.32)$ & $58.81(16.14)$ & 0.665 \\
\hline
\end{tabular}

Notes: aOthers: carcinoids, mucoepidermoid carcinoma, small cell carcinoma, adenocarcinoma, large cell carcinoma, and adenosquamous carcinoma. ${ }^{b} \mathrm{NRT}$ : training cohort $=7$ and validation cohort $=2$; PORT: training cohort $=106$ and validation cohort $=37$.

Abbreviations: ACC, adenoid cystic carcinoma; CHSDA, Contract Health Service Delivery Areas; NP, Northern Plains; NRT, neoadjuvant radiotherapy; PC, Pacific Coast; PORT, postoperative radiotherapy; RT, radiotherapy; SCC, squamous cell carcinoma; SW, Southwest. 
subtype was SCC. For both training and validation cohorts, most patients were classified in the E1, N0, and M0 stages and received either surgery or radiotherapy.

Table 2 summarizes the characteristics of the primary cohort across histological subtypes. SCC was primarily associated with elderly males, while ACC was more likely found in younger female patients. Compared to ACC and other histologies, patients with SCC also more likely experienced node metastasis and distant metastasis, and were more likely to have undergone radiotherapy. However, among patients who received both radiotherapy and surgery, ACC was the predominant subtype.

\section{Univariate and multivariate Cox regression of the training cohort}

For the training cohort, univariate analyses were performed to identify clinical variables that were significantly associated with OS and CSS. As shown in Table 3, age, race, gender, histological subtypes, treatment types, E, N, and M stages, and tumor size were significantly associated with OS. Regarding CSS, race lost its significance, while other variables continued to be significant parameters.

In the multivariate analysis, all of the original variables were initially entered into the Cox regression model. To determine the independent prognostic factors in this cohort, which could be adopted into the nomograms, we used the least value of AIC to select variables consistent with previous study. ${ }^{25}$ Age, marital status, histological subtypes, treatment, N stage, M stage, and tumor size were identified as prognostic factors for OS. Regarding CSS, marital status was excluded, while gender became significant indicator. The results of multivariate Cox regression are demonstrated in Table 4.

Table 2 Clinicopathological characteristics of primary tracheal patients in each histologic group

\begin{tabular}{|c|c|c|c|c|c|}
\hline Characteristic & & $\begin{array}{l}S C C \\
(n=162)\end{array}$ & $\begin{array}{l}\text { ACC } \\
(n=109)\end{array}$ & $\begin{array}{l}\text { Others }^{a} \\
(n=134)\end{array}$ & $P$-value \\
\hline Race (\%) & $\begin{array}{l}\text { White } \\
\text { Black } \\
\text { Others }\end{array}$ & $\begin{array}{l}133(82.1) \\
22(13.6) \\
7(4.3)\end{array}$ & $\begin{array}{l}80(73.4) \\
8(7.3) \\
21(19.3)\end{array}$ & $\begin{array}{l}102(76.1) \\
18(13.4) \\
14(10.4)\end{array}$ & 0.002 \\
\hline $\operatorname{Sex}(\%)$ & $\begin{array}{l}\text { Female } \\
\text { Male }\end{array}$ & $\begin{array}{l}58(35.8) \\
104(64.2)\end{array}$ & $\begin{array}{l}63(57.8) \\
46(42.2)\end{array}$ & $\begin{array}{l}59(44.0) \\
75(56.0)\end{array}$ & 0.002 \\
\hline Year of diagnosis (\%) & $\begin{array}{l}1988-1999 \\
2000-2009 \\
2010-2015\end{array}$ & $\begin{array}{l}31(19.1) \\
86(53.1) \\
45(27.8)\end{array}$ & $\begin{array}{l}17(15.6) \\
49(45.0) \\
43(39.4)\end{array}$ & $\begin{array}{l}29(21.6) \\
68(50.7) \\
37(27.6)\end{array}$ & 0.231 \\
\hline CHSDA region (\%) & $\begin{array}{l}\text { East } \\
\text { NP } \\
\text { PC } \\
\text { SW }\end{array}$ & $\begin{array}{l}70(43.2) \\
23(14.2) \\
57(35.2) \\
12(7.4)\end{array}$ & $\begin{array}{l}29(26.6) \\
13(11.9) \\
59(54.1) \\
8(7.3)\end{array}$ & $\begin{array}{l}43(32.1) \\
26(19.4) \\
58(43.3) \\
7(5.2)\end{array}$ & 0.028 \\
\hline Treatment (\%) & $\begin{array}{l}\text { None } \\
\text { RT + surgery } \\
\text { RT only } \\
\text { Surgery only }\end{array}$ & $\begin{array}{l}17(10.5) \\
53(32.7) \\
76(46.9) \\
16(9.9)\end{array}$ & $\begin{array}{l}3(2.8) \\
66(60.6) \\
18(16.5) \\
22(20.2)\end{array}$ & $\begin{array}{l}19(14.2) \\
33(24.6) \\
37(27.6) \\
45(33.6)\end{array}$ & $<0.001$ \\
\hline E stage (\%) & $\begin{array}{l}\text { EI } \\
\text { E2 } \\
\text { E3 }\end{array}$ & $\begin{array}{l}70(43.2) \\
82(50.6) \\
10(6.2)\end{array}$ & $\begin{array}{l}59(54.1) \\
50(45.9) \\
0(0.0)\end{array}$ & $\begin{array}{l}85(63.4) \\
47(35.1) \\
2(1.5)\end{array}$ & 0.001 \\
\hline $\mathrm{N}$ stage (\%) & $\begin{array}{l}\text { No } \\
\text { NI }\end{array}$ & $\begin{array}{l}100(61.7) \\
62(38.3)\end{array}$ & $\begin{array}{l}96(88.1) \\
13(11.9)\end{array}$ & $\begin{array}{l}98(73.1) \\
36(26.9)\end{array}$ & $<0.001$ \\
\hline M stage (\%) & $\begin{array}{l}\text { MO } \\
\text { MI }\end{array}$ & $\begin{array}{l}142(87.7) \\
20(12.3)\end{array}$ & $\begin{array}{l}102(93.6) \\
7(6.4)\end{array}$ & $\begin{array}{l}118(88.1) \\
16(11.9)\end{array}$ & 0.249 \\
\hline Tumor size (\%) & $\begin{array}{l}\leq 3.9 \mathrm{~cm} \\
>3.9 \mathrm{~cm} \\
\text { Unknown }\end{array}$ & $\begin{array}{l}68(65.4) \\
36(34.6) \\
58\end{array}$ & $\begin{array}{l}71(78.9) \\
19(21.1) \\
19\end{array}$ & $\begin{array}{l}70(73.7) \\
25(26.3) \\
39\end{array}$ & 0.104 \\
\hline $\begin{array}{l}\text { Marital status (\%) } \\
\text { Age, mean (SD) }\end{array}$ & $\begin{array}{l}\text { No } \\
\text { Yes } \\
\text { Unknown }\end{array}$ & $\begin{array}{l}79(51.3) \\
75(48.7) \\
8 \\
63.70(11.33)\end{array}$ & $\begin{array}{l}39(36.8) \\
67(63.2) \\
3 \\
53.22(15.96)\end{array}$ & $\begin{array}{l}55(43.3) \\
72(56.7) \\
7 \\
59.19(17.74)\end{array}$ & $\begin{array}{l}0.162 \\
<0.001\end{array}$ \\
\hline
\end{tabular}

Notes: a ${ }^{\circ}$ thers: carcinoids, mucoepidermoid carcinoma, small cell carcinoma, adenocarcinoma, large cell carcinoma, adenosquamous carcinoma. ${ }^{\circ} \mathrm{NRT}$ : SCC $=5$, ACC $=3$, and Others $=$ I; PORT: $S C C=48, A C C=63$, and Others $=32$.

Abbreviations: ACC, adenoid cystic carcinoma; CHSDA, Contract Health Service Delivery Areas; NP, Northern Plains; NRT, neoadjuvant radiotherapy; PC, Pacific Coast; PORT, postoperative radiotherapy; RT, radiotherapy; SCC, squamous cell carcinoma; SW, Southwest. 
Table 3 Univariate analysis of clinical characteristics for OS and CSS in primary tracheal patients in the training cohort

\begin{tabular}{|c|c|c|c|c|}
\hline \multirow[t]{2}{*}{ Characteristics } & \multicolumn{2}{|l|}{ OS } & \multicolumn{2}{|l|}{ CSS } \\
\hline & HR (95\% Cl) & $P$-value & HR (95\% Cl) & $P$-value \\
\hline Race & & 0.034 & & 0.071 \\
\hline White & Reference & & Reference & \\
\hline Black & $1.150(0.740-1.770)$ & 0.541 & $1.040(0.640-1.690)$ & 0.877 \\
\hline Others & $0.480(0.270-0.870)$ & 0.016 & $0.560(0.310-1.030)$ & 0.060 \\
\hline \multicolumn{5}{|l|}{ Sex } \\
\hline Female & Reference & & Reference & \\
\hline Male & $1.420(1.040-1.930)$ & 0.025 & $1.530(1.100-2.130)$ & 0.012 \\
\hline CHSDA region & & 0.225 & & 0.576 \\
\hline East & Reference & & Reference & \\
\hline NP & $1.000(0.640-1.550)$ & 0.997 & $0.930(0.580-1.510)$ & 0.780 \\
\hline PC & $0.740(0.530-1.040)$ & 0.082 & $0.720(0.500-1.040)$ & 0.081 \\
\hline sW & $0.620(0.290-1.360)$ & 0.236 & $0.720(0.330-1.580)$ & 0.409 \\
\hline Histology & & 0.013 & & 0.014 \\
\hline SCC & Reference & & Reference & \\
\hline ACC & $0.190(0.120-0.310)$ & $<0.001$ & $0.210(0.120-0.350)$ & $<0.001$ \\
\hline Others & $0.670(0.480-0.930)$ & 0.017 & $0.690(0.480-0.980)$ & 0.036 \\
\hline Treatment & & 0.012 & & 0.013 \\
\hline None & Reference & & Reference & \\
\hline RT + surgery & $0.270(0.160-0.440)$ & $<0.001$ & $0.280(0.170-0.460)$ & $<0.001$ \\
\hline RT only & $0.800(0.510-1.270)$ & 0.349 & $0.760(0.470-1.230)$ & 0.264 \\
\hline Surgery only & $0.150(0.080-0.290)$ & $<0.001$ & $0.130(0.060-0.270)$ & $<0.001$ \\
\hline \multicolumn{5}{|l|}{ E stage } \\
\hline EI & Reference & & Reference & \\
\hline E2 & $1.530(1.140-2.070)$ & 0.005 & $1.650(1.190-2.280)$ & 0.002 \\
\hline$E 3^{a}$ & - & & - & \\
\hline \multicolumn{5}{|l|}{ N stage } \\
\hline No & Reference & & Reference & \\
\hline $\mathrm{NI}$ & $3.190(2.320-4.390)$ & $<0.001$ & $3.610(2.580-5.050)$ & $<0.001$ \\
\hline \multicolumn{5}{|l|}{ M stage } \\
\hline MO & Reference & & Reference & \\
\hline MI & $3.270(2.120-5.030)$ & $<0.001$ & $3.530(2.260-5.500)$ & $<0.001$ \\
\hline Tumor size $(\mathrm{cm})$ & & $<0.001$ & & $<0.001$ \\
\hline$\leq 3.9$ & Reference & & Reference & \\
\hline$>3.9$ & $2.470(1.660-3.680)$ & $<0.001$ & $2.580(1.700-3.930)$ & $<0.001$ \\
\hline Unknown & $2.760(1.960-3.890)$ & $<0.001$ & $2.690(1.860-3.900)$ & $<0.001$ \\
\hline Marital status & & 0.121 & & 0.224 \\
\hline No & Reference & & Reference & \\
\hline Yes & $0.790(0.580-1.070)$ & 0.131 & $0.770(0.550-1.070)$ & 0.115 \\
\hline Unknown & $1.700(0.820-3.520)$ & 0.157 & $1.390(0.600-3.210)$ & 0.442 \\
\hline Age & $1.050(1.040-1.060)$ & $<0.001$ & $1.050(1.030-1.060)$ & $<0.001$ \\
\hline
\end{tabular}

Notes: ${ }^{\mathrm{E}} \mathrm{E} 3$ stage were too few to calculate accurately. RT + surgery: NRT $=7$ and PORT $=105$.

Abbreviations: CHSDA, Contract Health Service Delivery Areas; CSS, cancer-specific survival; NP, Northern Plains; NRT, neoadjuvant radiotherapy; OS, overall survival; PC, Pacific Coast; PORT, postoperative radiotherapy; RT, radiotherapy; SW, Southwest.

\section{Construction of nomogram for OS and CSS}

Nomograms for predicting 1- and 5-year OS (Figure 1A) and CSS (Figure 1B) were constructed by using the covariates mentioned above, and score details of each nomogram predictor are shown in Table 5. By adding the scores of all the selected variables, the probabilities of survival of the individual patients could be accurately determined.

\section{Validation of the nomograms}

The C-indices of the nomograms to predict OS were 0.813 (95\% CI: 0.764-0.862) and 0.838 (95\% CI: 0.748-0.927) for the training and validation cohorts, respectively, exhibiting excellent consistency with actual OS. Similarly, when the training and validation cohorts were applied to the nomogram for CSS, the C-index values were also greater than 0.7 (0.817 and 0.863, respectively). As shown in Figure 2, both 





internal and external calibration curves for 1- and 5-year OS and CSS suggested strong agreement between the prediction by nomogram and the actual outcomes in the training and validation cohorts.

We further compared the OS/CSS predictive ability between the nomogram and Bhattacharyya's staging system. As shown in Table 6, the $\mathrm{C}$-indices of the nomograms were significantly higher than those of the Bhattacharyya's staging system for both OS and CSS (C-index: OS 0.810 vs. 0.660 , $P<0.001$; CSS 0.820 vs. $0.700, P<0.001)$.

\section{Value of PORT for tracheal patients}

For the purpose of evaluating the prognostic value of PORT comprehensively, a PSM analysis was conducted between patients who received surgical resection, either with or without PORT, based on age, race, gender, CHSDA region, histological subtypes, E, N, and M stages, tumor size, and marital status. Ultimately, 76 patients with PORT and 76 patients without PORT were enrolled in the matching cohort (Table S1). In the matching cohort, there was no significant difference regarding clinical characteristics, and neither OS nor CSS were significantly different between the two groups. In the subgroup analysis, PORT was not associated with superior outcome for ACC (figures not shown). Patients with SCC who received PORT had significantly better prognoses compared with those who did not, though only for OS (5-year OS: $61.5 \%$ vs $23.0 \%, P<0.05$; Figure $\mathrm{S} 1$ ).

\section{Discussion}

Due to the extremely low incidence of primary tracheal tumors, neither an AJCC staging system nor a reliable guideline for the management of these uncommon neoplasms has been established. Previously published investigations were primarily composed of case reports, reviews, and singleinstitutional experience. ${ }^{1,3,7,26}$ No large-scale study regarding the prognostic factors of tracheal tumors has been reported. As the graphical depictions of statistical models, nomograms have been used to predict individual survival outcomes among patients with other diseases. ${ }^{27-29}$ Because a multitude of advantages have been suggested, prognostic nomograms are widely accepted in clinical practice. By using the SEER dataset, we build two novel, user-friendly, and accurate nomograms for predicting the overall and disease-specific survival for patients with primary tracheal tumors. To the best of our knowledge, this study is the first to develop clinicopathological prediction models based on a large series of patients for this unique condition. Both internal and external validations of our nomograms showed effective discrimination. 
A

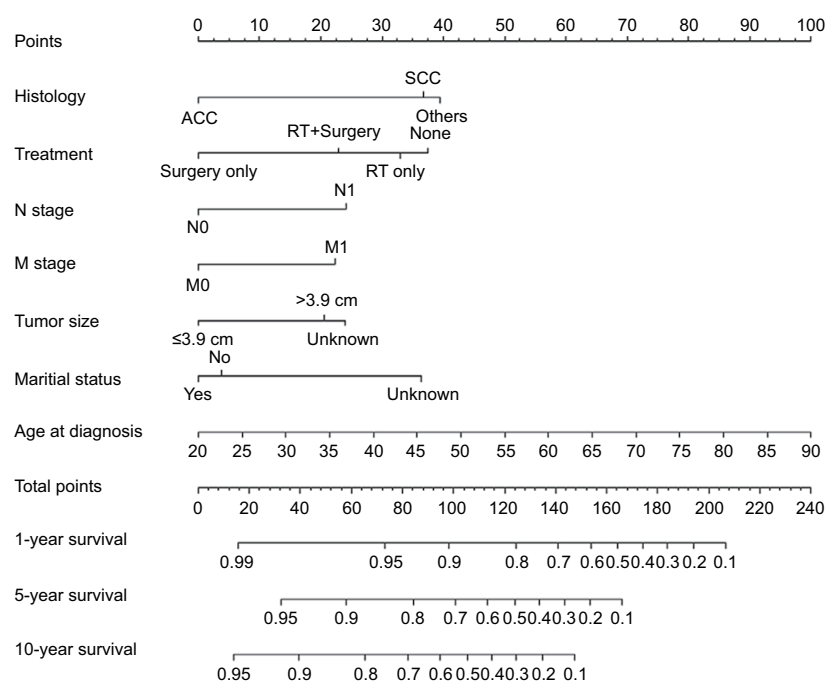

B

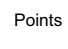

Histology

Sex

Treatment

$\mathrm{N}$ stage

M stage

Tumor size

Age at diagnosis

Total points

1-year survival

5-year survival

10-year survival

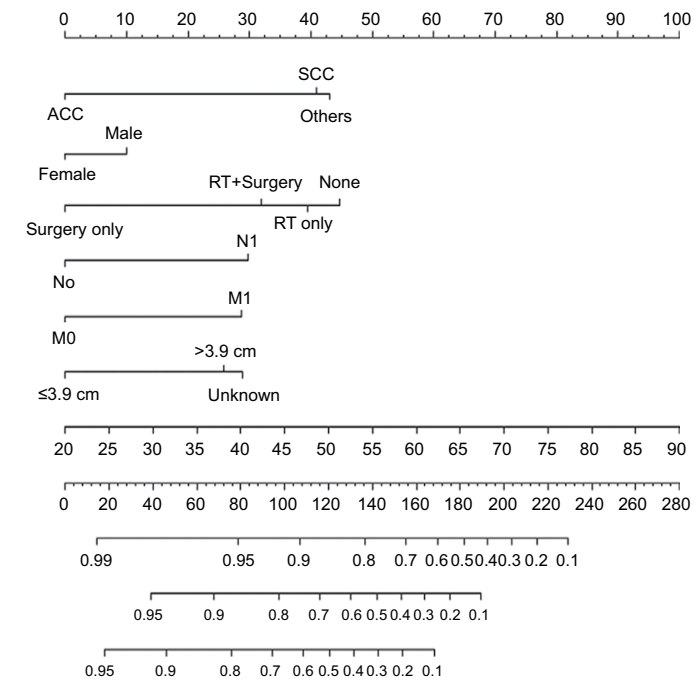

Figure I Nomograms for predicting (A) I- and 5-year OS and (B) CSS of primary tracheal tumors.

The absence of a universally adopted staging system made it difficult for clinicians to properly assess tracheal neoplasms. Until the present, only three studies stated their proposed guidelines for the staging of tracheal malignancy. One staging system, suggested by Licht et al, was based on limited number of patients and thus lacked sufficient prognostic value. ${ }^{7}$ In 2006, Macchiarini et $\mathrm{al}^{1}$ proposed a more elaborate system, which references the experience of head and neck malignancies. However, the lack of external validation has restricted the usage of this staging model. Only one staging system, proposed by Bhattacharyya ${ }^{20}$ has been validated and modified by another study. ${ }^{3}$ Therefore, we compared our models with Bhattacharyya's staging system and found the discrimination performance of our nomograms superior to Bhattacharyya's classification. Moreover, the previous staging system ignored patients with nonregional lymph node or distant organ metastases and utilized data from patients diagnosed in the last century. In the present study, we selected several accessible parameters that reflect tumor characteristics, as well as patient status, to build comprehensive nomograms for tracheal neoplasm patients.

Our study identified several clinicopathological characteristics as important prognostic factors for OS and CSS among patients with tracheal tumors. As expected, the effect of age at diagnosis was highly significant for both OS and CSS. Prior studies focused on other malignancies also suggested that elderly patients always had worse survival than younger ones. ${ }^{30,31}$ Younger patients are believed to tolerate more aggressive treatment modalities than older patients. This tolerance could explain the differences of survival outcomes between these two groups. In ACCs, early detection has also been reported to associate with increased resectability rates and even improved survival. ${ }^{6}$ Another interesting finding was that females had better CSS than males. We noted that females were more likely to suffer from ACCs, while SCCs were more common among males. The survival difference among males compared to females could partly be explained by the different tumor biology behavior between ACCs and SCCs. Wang et $\mathrm{al}^{32}$ reported that consultation rates were significantly different between men and women, with men being more likely to endure symptoms for a long period and thus develop advanced disease with a less favorable prognosis, which could also be one explanation for the present study. Moreover, married patients had superior OS than their unmarried competitors. One explanation for this could be the difference in health-care seeking behavior between married and unmarried patients. ${ }^{33,34}$

In our analysis, histological type was an important issue for both OS and CSS, and was included in our nomograms. Patients with SCCs at diagnosis had inferior outcomes than those with ACCs, with 5- and 10-year OS rates for ACCs of $79.0 \%$ and $62.3 \%$, respectively, compared to $25.8 \%$ and $15.6 \%$ for SCCs, respectively (figures not shown). Our finding was consistent with those of previous studies. Gaissert et $\mathrm{al}^{9}$ compared the survival outcomes between 101 patients with ACCs and 90 patients with SCCs and found that the prognosis of ACCs was significantly superior to SCCs (5-year OS $52 \%$ vs. $39 \%, P<0.001)$. Another study based on oriental populations ${ }^{35}$ also suggested an approximately twofold 5 -year survival rate disparity between these two subtypes. 
Table 5 Points of prognostic factors in the nomograms

\begin{tabular}{|c|c|c|}
\hline Characteristics & OS & CSS \\
\hline \multicolumn{3}{|l|}{ Sex } \\
\hline Female & Not selected & 0 \\
\hline Male & & 10 \\
\hline \multicolumn{3}{|l|}{ Histology } \\
\hline SCC & 39 & 41 \\
\hline ACC & 0 & 0 \\
\hline Others & 41 & 43 \\
\hline \multicolumn{3}{|l|}{ Treatment } \\
\hline None & 38 & 45 \\
\hline RT + surgery & 24 & 32 \\
\hline RT only & 35 & 39 \\
\hline Surgery only & 0 & 0 \\
\hline \multicolumn{3}{|l|}{ N stage } \\
\hline No & 0 & 0 \\
\hline $\mathrm{NI}$ & 25 & 30 \\
\hline \multicolumn{3}{|l|}{ M stage } \\
\hline M0 & 0 & 0 \\
\hline $\mathrm{MI}$ & 23 & 29 \\
\hline \multicolumn{3}{|l|}{ Tumor size (cm) } \\
\hline$\leq 3.9$ & 0 & 0 \\
\hline$>3.9$ & 21 & 26 \\
\hline Unknown & 27 & 29 \\
\hline \multicolumn{3}{|l|}{ Marital status } \\
\hline No & 3 & Not selected \\
\hline Yes & 0 & \\
\hline Unknown & 37 & \\
\hline \multicolumn{3}{|l|}{ Age (years) } \\
\hline 20 & 0 & 0 \\
\hline 25 & 7 & 7 \\
\hline 30 & 14 & 14 \\
\hline 35 & 21 & 21 \\
\hline 40 & 29 & 29 \\
\hline 45 & 36 & 36 \\
\hline 50 & 43 & 43 \\
\hline 55 & 50 & 50 \\
\hline 60 & 57 & 57 \\
\hline 65 & 64 & 64 \\
\hline 70 & 71 & 71 \\
\hline 75 & 79 & 79 \\
\hline 80 & 86 & 86 \\
\hline 85 & 93 & 93 \\
\hline 90 & 100 & 100 \\
\hline
\end{tabular}

Abbreviations: ACC, adenoid cystic carcinoma; CSS, cancer-specific survival; OS, overall survival; RT, radiotherapy; SCC, squamous cell carcinoma.

In our study, SCCs were more likely to present with local extension, as well as lymph node metastasis, than ACCs at diagnosis. Our study, together with published reports, might indicate different genetic alterations and tumor biology in different histological subgroups; however, further studies are warranted to evaluate this issue.

The presence of lymph node metastasis was found to be a poor prognostic indicator in our study, which has also been supported by a previous epidemiological study ${ }^{20}$ For distant metastasis, our study innovatively classified nonregional node metastasis and distant organ metastasis as M1, which was consequently incorporated into the nomograms via the AIC-based selections. According to a prior study reviewing their 40 years of experience with treatment of ACC and SCC, Gaissert et al observed distant metastasis in $10 \%$ of diagnoses. Because the information of site-specific metastases was not collected until 2010, we further analyzed the metastatic patterns of tracheal tumor patients by querying the SEER database from 2010 through 2015. Among 125 eligible patients, the most frequent metastatic site was lung (16 patients, $12.8 \%$ ) followed by liver ( 7 patients, $5.6 \%$ ). The incidences of bone and brain metastases were $3.2 \%$ and $1.6 \%$, respectively. In 1996, Maziak et al ${ }^{8}$ evaluated the proportion of metachronous metastases in 17 patients, which was in keeping with our findings. However, our study recruited a larger cohort and demonstrated the patterns of site-specific metastasis in primary tracheal malignancies for the first time. It is not a surprise to find that the tumor extension was not an independent prognostic indicator for OS and CSS in our study. In fact, the size and location of the primary tumor have been reported to be more important than the extension of tumors. ${ }^{36,37}$ Another serial study ${ }^{9}$ also suggested that more advanced tumor extension might not correlate with higher mortality risk. Referring to the prognostic value of tumor size, our study selected $3.9 \mathrm{~cm}$ as the cutoff point, which was similar with Macchiarini's study. ${ }^{1}$ Simultaneously, the AIC-based analyses demonstrated that those with tumor size $<3.9 \mathrm{~cm}$ were associated with better prognosis.

Complete surgical resection with negative margins (R0 resection) has always been considered to be the mainstay strategy for tracheal tumors. ${ }^{6,38}$ Our study revealed that patients who underwent surgery had better survival outcomes compared to nonsurgery patients. However, due to the nature of the SEER database, details of surgical margins were lacking. Further large-scale studies examining the value of R0 resection compared to $\mathrm{R} 1$, and even $\mathrm{R} 2$, resection is needed. The role of PORT remains controversial. Few reports ${ }^{12,39}$ suggested that PORT seems to be effective for R1/R2 resected disease. However, these two studies are limited by small sample size and were less likely to provide sufficient information to determine the prognostic value of PORT. Xie et a $\mathrm{a}^{40}$ conducted a population-based study to investigate this issue but did not separate PORT from neoadjuvant radiotherapy. Honings et $\mathrm{a}^{10,14}$ even drew a contradictory conclusion. To adjust for potential selection bias, we used the PSM method and evaluated the survival benefit from PORT in patients who received surgery: the favorable impact of PORT was only found for 
SCC patients. However, this should be taken cautiously due to the fact that the sample size was relatively limited and was from subgroup analysis. Previous studies have suggested lower radiosensitivity for ACC while neutron radiotherapy seems to improve the local-regional control for this condition. ${ }^{41}$ In contrast, Schraube et $\mathrm{al}^{42}$ and Jeremic et $\mathrm{al}^{11}$ noted significantly improved survival among SCC patients who underwent radiotherapy. Conversely, Yang et $\mathrm{ll}^{6}$ suggested that ACC patients with $\mathrm{R} 1$ resection showed improved disease free survival of PORT but not in terms of OS. Our study, together with previous studies, suggested that the exact role of PORT in influencing survival remains unclear.

Several inevitable limitations in our study should be considered. First, as mentioned above, information on tumor location, surgical margins, techniques, prescription dose as well as

A



C

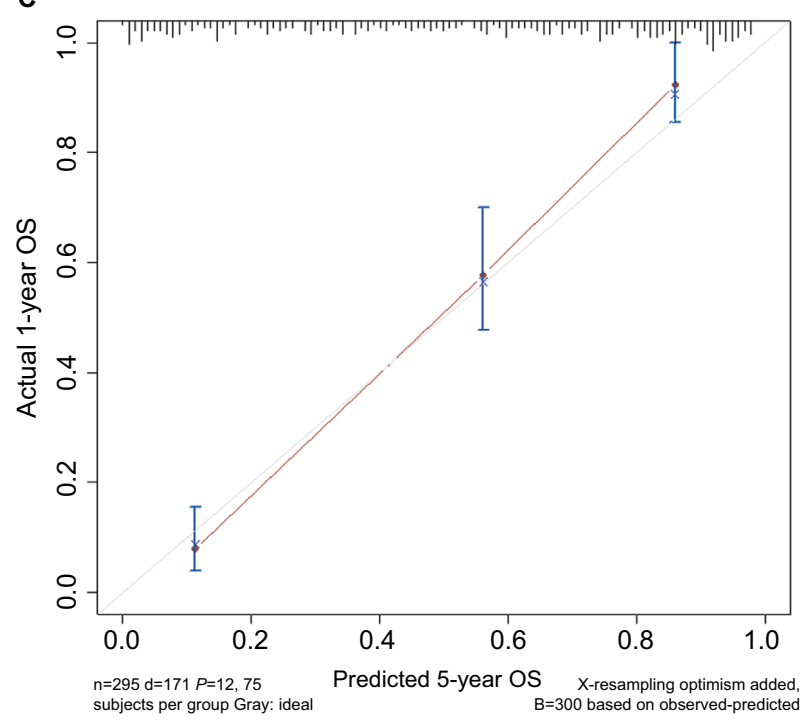

fraction times of radiotherapy could not be ascertained from SEER. Second, prior studies evaluating the role of chemotherapy in the treatment of tracheal tumors have generated mixed conclusions. However, we could not examine this issue due to the lack of chemotherapy information in the SEER database. Finally, the database also lacks recurrence, performance status, and laboratory and pathological parameters, which could be used to build a more comprehensive nomogram.

Despite the abovementioned limitations, as well as the rarity of primary tracheal malignancies, our study created and validated the first two nomograms based on the combination of both anatomic and non-anatomic parameters, including clinical and epidemiological features, by using a large population-based approach. PORT seems to improve the prognosis of SCC patients, which warrants further investigation.

B

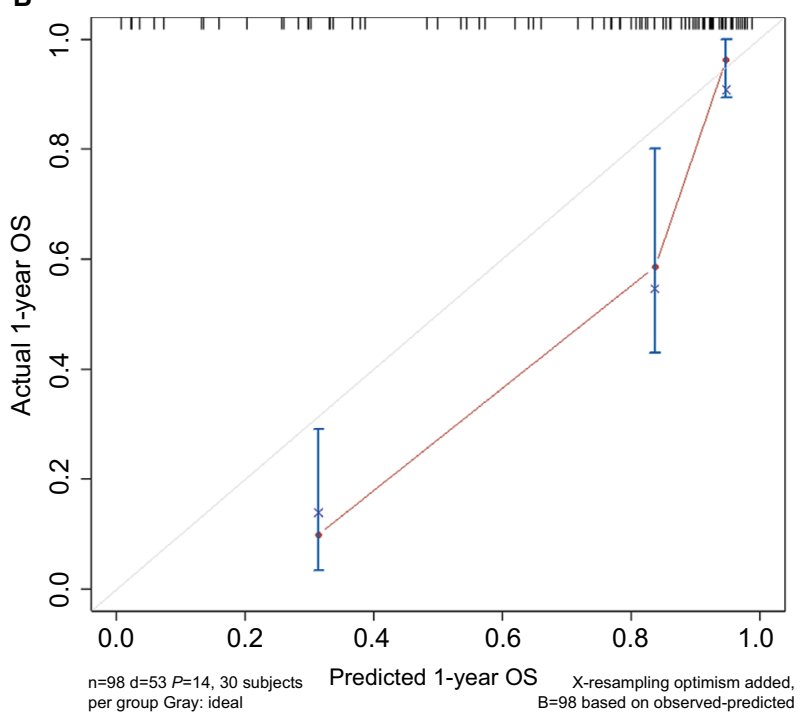

D

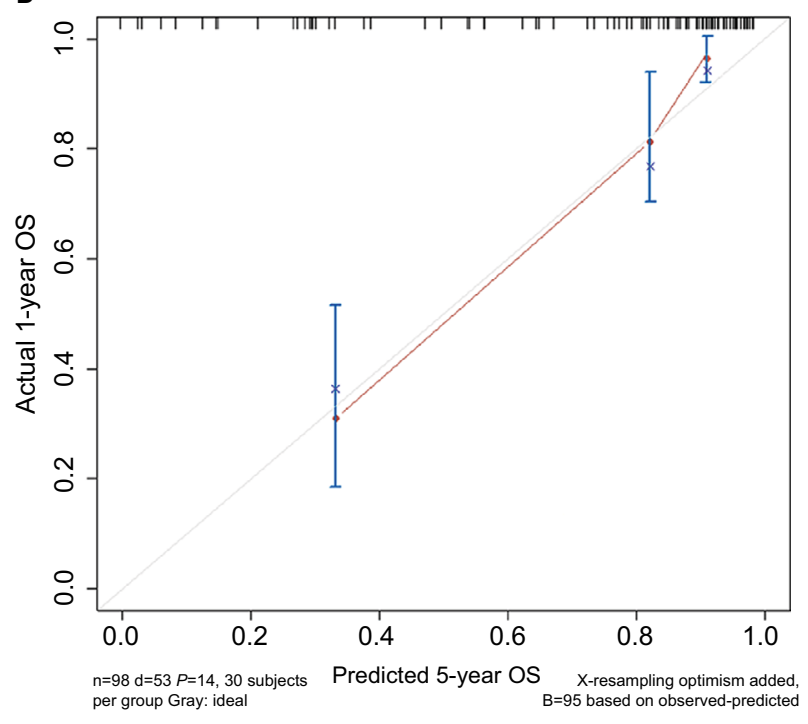

Figure 2 (Continued) 

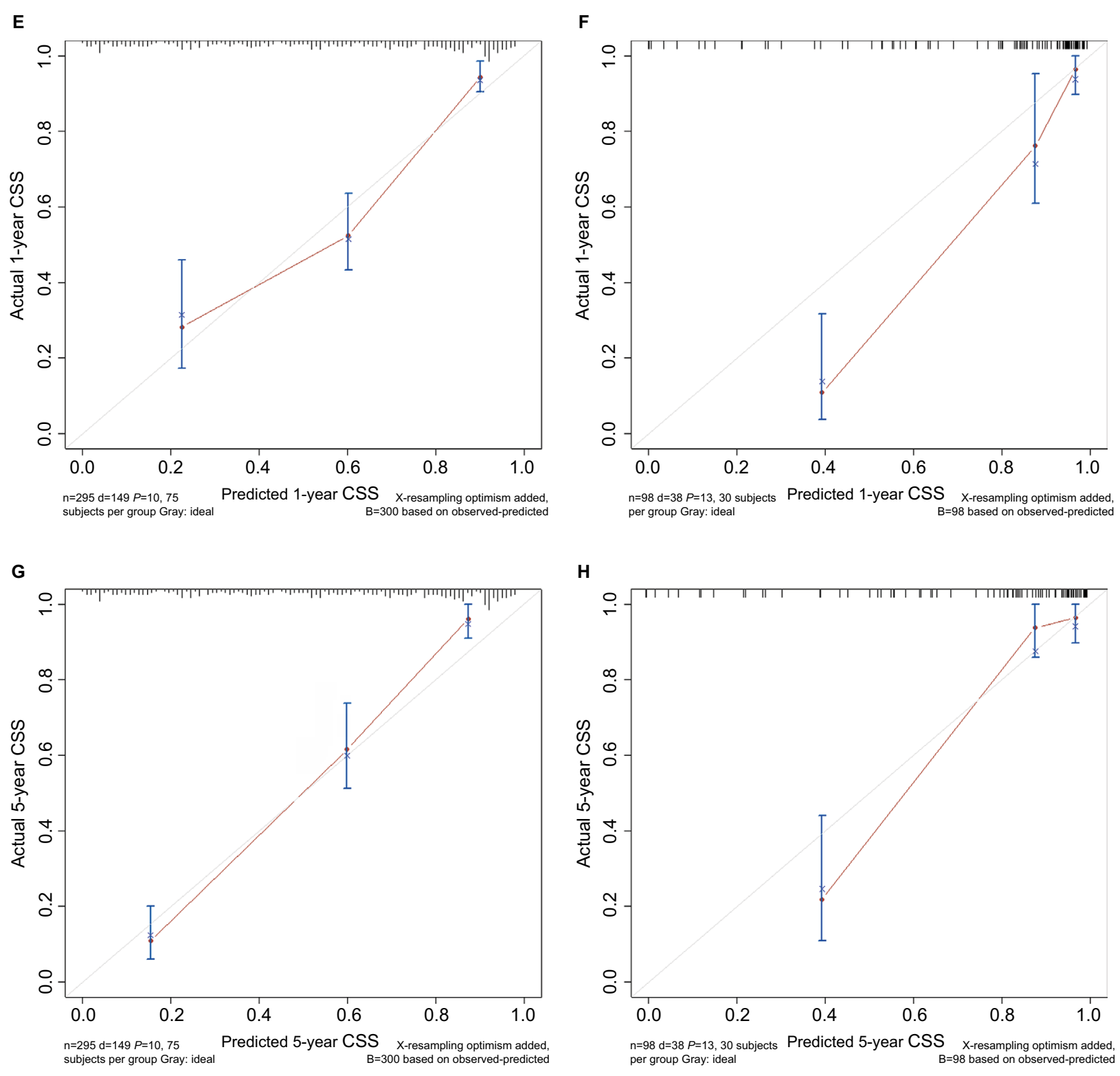

Figure 2 Calibration curves of (A and $\mathbf{C})$ I- and 5-year OS and (E and $\mathbf{G})$ CSS for training cohort, and (B and D) OS and (F and $\mathbf{H})$ CSS for validation cohort.

Table 6 Comparison of nomograms with Bhattacharyya's staging system

\begin{tabular}{|l|l|l|l|l|}
\hline \multirow{2}{*}{ Models } & \multicolumn{2}{l|}{ OS } & \multicolumn{1}{l|}{ CSS } \\
\cline { 2 - 5 } & C-index (95\% Cl) & $\boldsymbol{P}$-value & C-index (95\% Cl) & $\boldsymbol{P}$-value \\
\hline Nomogram (Model I) & $0.810(0.770-0.852)$ & - & $0.820(0.750-0.897)$ & - \\
Bhattacharyya stage (Model 2) & $0.660(0.600-0.710)$ & - & $0.700(0.640-0.760)$ & - \\
Model I vs. Model 2 & - & $<0.001$ & - & $<0.001$ \\
\hline
\end{tabular}

Abbreviations: CSS, cancer-specific survival; C-index, Harrell's concordance index; OS, overall survival.

\section{Acknowledgments}

This study was based on the publicly available SEER database, and permission was received from the National Cancer Institute to access the database for the purposes of research (the private
SEER ID 13499-Nov2016). As this research did not include interaction with humans or use personal identifying information, informed consent was not required. We thank the American Journal Experts (https://www.aje.com/) for editing this manuscript. 


\section{Disclosure}

The authors report no conflicts of interest in this work.

\section{References}

1. Macchiarini P, Schirren J, Muley T, Moykopf IV. Primary tracheal tumours. Lancet Oncol. 2006;7(1):83-91.

2. Nouraei SM, Middleton SE, Nouraei SA, et al. Management and prognosis of primary tracheal cancer: a national analysis. Laryngoscope. 2014;124(1):145-150.

3. Webb BD, Walsh GL, Roberts DB, Sturgis EM. Primary tracheal malignant neoplasms: the University of Texas MD Anderson Cancer Center experience. J Am Coll Surg. 2006;202(2):237-246.

4. Ahn Y, Chang H, Lim YS, et al. Primary tracheal tumors: review of 37 cases. J Thorac Oncol. 2009;4(5):635-638.

5. Honings J, Gaissert HA, Verhagen AF, et al. Undertreatment of tracheal carcinoma: multidisciplinary audit of epidemiologic data. Ann Surg Oncol. 2009;16(2):246-253.

6. Yang H, Yao F, Tantai J, Zhao Y, Tan Q, Zhao H. Resected tracheal adenoid cystic carcinoma: improvements in outcome at a single institution. Ann Thorac Surg. 2016;101(1):294-300.

7. Licht PB, Friis S, Pettersson G. Tracheal cancer in Denmark: a nationwide study. Eur J Cardiothorac Surg. 2001;19(3):339-345.

8. Maziak DE, Todd TR, Keshavjee SH, Winton TL, van Nostrand P, Pearson FG. Adenoid cystic carcinoma of the airway: thirty-two-year experience. J Thorac Cardiovasc Surg. 1996;112(6):1522-1532.

9. Gaissert HA, Grillo HC, Shadmehr MB, et al. Long-term survival after resection of primary adenoid cystic and squamous cell carcinoma of the trachea and carina. Ann Thorac Surg. 2004;78(6):1889-1897.

10. Honings J, van Dijck JA, Verhagen AF, van der Heijden HF, Marres HA. Incidence and treatment of tracheal cancer: a nationwide study in the Netherlands. Ann Surg Oncol. 2007;14(2):968-976.

11. Jeremic B, Shibamoto Y, Acimovic L, Milisavljevic S. Radiotherapy for primary squamous cell carcinoma of the trachea. Radiother Oncol. 1996;41(2):135-138.

12. Calzada AP, Miller M, Lai CK, Elashoff DA, Abemayor E, St John MA. Adenoid cystic carcinoma of the airway: a 30-year review at one institution. Am J Otolaryngol. 2012;33(2):226-231.

13. Allen AM, Rabin MS, Reilly JJ, Mentzer SJ. Unresectable adenoid cystic carcinoma of the trachea treated with chemoradiation. J Clin Oncol. 2007;25(34):5521-5523.

14. Honings J, Gaissert HA, Weinberg AC, et al. Prognostic value of pathologic characteristics and resection margins in tracheal adenoid cystic carcinoma. Eur J Cardiothorac Surg. 2010;37(6):1438-1444.

15. Urdaneta AI, Yu JB, Wilson LD. Population based cancer registry analysis of primary tracheal carcinoma. Am J Clin Oncol. 2011;34(1):32-37.

16. Valentini V, van Stiphout RG, Lammering G, et al. Nomograms for predicting local recurrence, distant metastases, and overall survival for patients with locally advanced rectal cancer on the basis of European randomized clinical trials. J Clin Oncol. 2011;29(23):3163-3172.

17. Karakiewicz PI, Briganti A, Chun FK, et al. Multi-institutional validation of a new renal cancer-specific survival nomogram. J Clin Oncol. 2007;25(11):1316-1322.

18. Song W, Zhu ZG, Wu Q, et al. A nomogram to predict overall survival for biliary tract cancer. Cancer Manag Res. 2018;10:1535-1541.

19. Surveillance, Epidemiology and End Results Program, About the SEER Program; 2018. Available from: https://seer.cancer.gov/about/overview. html, 2018. Accessed May, 5, 2018.

20. Bhattacharyya N. Contemporary staging and prognosis for primary tracheal malignancies: a population-based analysis. Otolaryngol Head Neck Surg. 2004;131(5):639-642.

21. Harrell FE, Lee KL, Mark DB. Multivariable prognostic models: issues in developing models, evaluating assumptions and adequacy, and measuring and reducing errors. Stat Med. 1996;15(4):361-387.
22. Harrell FE. Regression Modeling Strategies. New York, NY: Springer New York; 2001.

23. Frank EH. R Package version 3.9-2. Available from: https://cran.rproject.org/package=Hmisc. Accessed February 1, 2017.

24. Wen J, Chen J, Chen D, et al. Evaluation of the prognostic value of surgery and postoperative radiotherapy for patients with thymic neuroendocrine tumors: a propensity-matched study based on the SEER database. Thorac Cancer. 2018:1-11.

25. Zhang ZY, Luo QF, Yin XW, Dai ZL, Basnet S, Ge HY. Nomograms to predict survival after colorectal cancer resection without preoperative therapy. BMC Cancer. 2016;16(1):658.

26. Thotathil ZS, Agarwal JP, Shrivastava SK, Dinshaw KA. Primary malignant tumors of the trachea - the Tata Memorial Hospital experience. Med Princ Pract. 2004;13(2):69-73.

27. Kawai K, Ishihara S, Yamaguchi H, et al. Nomogram prediction of metachronous colorectal neoplasms in patients with colorectal cancer. Ann Surg. 2015;261(5):926-932.

28. Pilotto S, Sperduti I, Leuzzi G, et al. Prognostic Model for Resected Squamous Cell Lung Cancer: External Multicenter Validation and Propensity Score Analysis exploring the Impact of Adjuvant and Neoadjuvant Treatment. J Thorac Oncol. 2018;13(4):568-575.

29. Fakhry C, Zhang Q, Nguyen-Tân PF, et al. Development and validation of nomograms predictive of overall and progressionfree survival in patients with oropharyngeal cancer. J Clin Oncol. 2017;35(36):4057-4065.

30. Quaresma M, Coleman MP, Rachet B. 40-year trends in an index of survival for all cancers combined and survival adjusted for age and sex for each cancer in England and Wales, 1971-2011: a population-based study. Lancet. 2015;385(9974):1206-1218.

31. Skyrud KD, Bray F, Møller B. A comparison of relative and causespecific survival by cancer site, age and time since diagnosis. Int $J$ Cancer. 2014;135(1):196-203.

32. Wang Y, Hunt K, Nazareth I, Freemantle N, Petersen I. Do men consult less than women? An analysis of routinely collected UK general practice data. BMJ Open. 2013;3(8): $\mathrm{e} 003320$-e003327.

33. Wu W, Fang D, Shi D, Bian X, Li L. Effects of marital status on survival of hepatocellular carcinoma by race/ethnicity and gender. Cancer Manag Res. 2018;10:23-32.

34. Gomez SL, Hurley S, Canchola AJ, et al. Effects of marital status and economic resources on survival after cancer: a population-based study. Cancer. 2016;122(10):1618-1625.

35. Zhengjaiang L, Pingzhang T, Dechao Z, Reddy-Kolanu G, Ilankovan V. Primary tracheal tumours: 21 years of experience at Peking Union Medical College, Beijing, China. J Laryngol Otol. 2008;122(11):1235.

36. Gelder CM, Hetzel MR. Primary tracheal tumours: a national survey. Thorax. 1993;48(7):688-692.

37. Allen MS. Malignant tracheal tumors. Mayo Clin Proc. 1993;68(7): 680-684.

38. D'Cunha J, Maddaus MA. Surgical treatment of tracheal and carinal tumors. Chest Surg Clin NAm. 2003;13(1):95-110.

39. Ogino T, Ono R, Shimizu W, Ikeda H. Adenoid cystic carcinoma of the tracheobronchial system: the role of postoperative radiotherapy. Radiat Med. 1995;13(1):27-29.

40. Xie L, Fan M, Sheets NC, Chen RC, Jiang GL, Marks LB. The use of radiation therapy appears to improve outcome in patients with malignant primary tracheal tumors: a SEER-based analysis. Int J Radiat Oncol Biol Phys. 2012;84(2):464-470.

41. Douglas JG, Laramore GE, Austin-Seymour M, Koh W, Stelzer K, Griffin TW. Treatment of locally advanced adenoid cystic carcinoma of the head and neck with neutron radiotherapy. Int J Radiat Oncol Biol Phys. 2000;46(3):551-557.

42. Schraube P, Latz D, Wannenmacher M. Treatment of primary squamous cell carcinoma of the trachea: the role of radiation therapy. Radiother Oncol. 1994;33(3):254-258. 


\section{Supplementary material}

Table SI Patient characteristics according to the administration of PORT before and after PSM

\begin{tabular}{|c|c|c|c|c|c|c|c|}
\hline \multicolumn{2}{|l|}{ Characteristics } & \multicolumn{3}{|l|}{ Before PSM } & \multicolumn{3}{|l|}{ After PSM } \\
\hline & & \multirow{2}{*}{$\begin{array}{l}\text { PORT(-) } \\
(n=83)\end{array}$} & \multirow{2}{*}{$\begin{array}{l}\begin{array}{l}\text { PORT(+) } \\
(n=143)\end{array} \\
108(75.5)\end{array}$} & \multirow{2}{*}{$\begin{array}{l}P \text {-value } \\
0.621\end{array}$} & \multirow{2}{*}{ 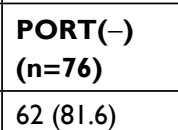 } & \multirow{2}{*}{$\begin{array}{l}\begin{array}{l}\text { PORT(+) } \\
(n=76)\end{array} \\
58(76.3)\end{array}$} & \multirow{2}{*}{$\begin{array}{l}P \text {-value } \\
0.726\end{array}$} \\
\hline Race (\%) & White & & & & & & \\
\hline & Black & $7(8.4)$ & $18(12.6)$ & & $6(7.9)$ & $8(10.5)$ & \\
\hline & Others & II (I3.3) & $17(11.9)$ & & $8(10.5)$ & $10(13.2)$ & \\
\hline \multirow[t]{2}{*}{ Sex (\%) } & Female & $44(53.0)$ & $70(49.0)$ & 0.652 & $40(52.6)$ & $39(51.3)$ & 1.000 \\
\hline & Male & $39(47.0)$ & $73(51.0)$ & & $36(47.4)$ & 37 (48.7) & \\
\hline \multirow[t]{3}{*}{ Year of diagnosis (\%) } & $1988-1999$ & $16(19.3)$ & $34(23.8)$ & 0.719 & $16(21.1)$ & $16(21.1)$ & 0.655 \\
\hline & $2000-2009$ & $4 I(49.4)$ & $65(45.5)$ & & $36(47.4)$ & $31(40.8)$ & \\
\hline & $2010-2015$ & $26(31.3)$ & $44(30.8)$ & & $24(31.6)$ & $29(38.2)$ & \\
\hline \multirow[t]{4}{*}{ CHSDA region (\%) } & East & $23(27.7)$ & $42(29.4)$ & 0.696 & $19(25.0)$ & $20(26.3)$ & 0.725 \\
\hline & NP & $12(14.5)$ & $24(16.8)$ & & $38(50.0)$ & $33(43.4)$ & \\
\hline & PC & $40(48.2)$ & $69(48.3)$ & & $12(15.8)$ & $17(22.4)$ & \\
\hline & sW & $8(9.6)$ & $8(5.6)$ & & $7(9.2)$ & $6(7.9)$ & \\
\hline \multirow[t]{3}{*}{ Histology (\%) } & SCC & $16(19.3)$ & $48(33.6)$ & $<0.001$ & $16(21.1)$ & $14(18.4)$ & 0.056 \\
\hline & $A C C$ & $22(26.5)$ & $63(44.1)$ & & $22(28.9)$ & $36(47.4)$ & \\
\hline & Others & $45(54.2)$ & $32(22.4)$ & & $38(50.0)$ & $26(34.2)$ & \\
\hline \multirow[t]{3}{*}{ E stage (\%) } & EI & $59(7 \mid .1)$ & $74(51.7)$ & 0.013 & $52(68.4)$ & $49(64.5)$ & 0.731 \\
\hline & E2 & $24(28.9)$ & $67(46.9)$ & & $24(31.6)$ & $27(35.5)$ & \\
\hline & E3 & $0(0.0)$ & $2(1.4)$ & & 0 & 0 & \\
\hline \multirow[t]{2}{*}{$\mathrm{N}$ stage (\%) } & No & $78(94.0)$ & II (77.6) & 0.003 & 71 (93.4) & $69(90.8)$ & 0.764 \\
\hline & NI & $5(6.0)$ & $32(22.4)$ & & $5(6.6)$ & $7(9.2)$ & \\
\hline \multirow[t]{2}{*}{ M stage (\%) } & Mo & $78(94.0)$ & $134(93.7)$ & 1.000 & $72(94.7)$ & $70(92.1)$ & 0.744 \\
\hline & MI & $5(6.0)$ & $9(6.3)$ & & $4(5.3)$ & $6(7.9)$ & \\
\hline \multirow[t]{3}{*}{ Tumor size (\%) } & $\leq 3.9 \mathrm{~cm}$ & $51(75.0)$ & $99(86.1)$ & 0.092 & $47(74.6)$ & $52(83.9)$ & 0.271 \\
\hline & $>3.9 \mathrm{~cm}$ & $17(25.0)$ & $16(13.9)$ & & $16(25.4)$ & $10(16.1)$ & \\
\hline & Unknown & 15 & 28 & & 13 & 14 & \\
\hline \multirow[t]{3}{*}{ Marital status (\%) } & No & $40(50.6)$ & $50(36.0)$ & 0.049 & 39 (53.4) & $42(58.3)$ & 0.617 \\
\hline & Yes & $39(49.4)$ & $89(64.0)$ & & $34(46.6)$ & $30(41.7)$ & \\
\hline & Unknown & 4 & 4 & & 3 & 4 & \\
\hline Age (mean [SD]) & & $55.07(19.66)$ & $56.4 \mathrm{I}(14.42)$ & 0.559 & $55.75(19.14)$ & $56.4 \mid(I 5.22)$ & 0.815 \\
\hline
\end{tabular}

Abbreviations: ACC,_adenoid cystic carcinoma; CHSDA, Contract Health Service Delivery Areas; NP, Northern Plains; PC, Pacific Coast; PORT, postoperative radiotherapy; PSM, propensity score matching; SCC, squamous cell carcinoma; SW, Southwest. 


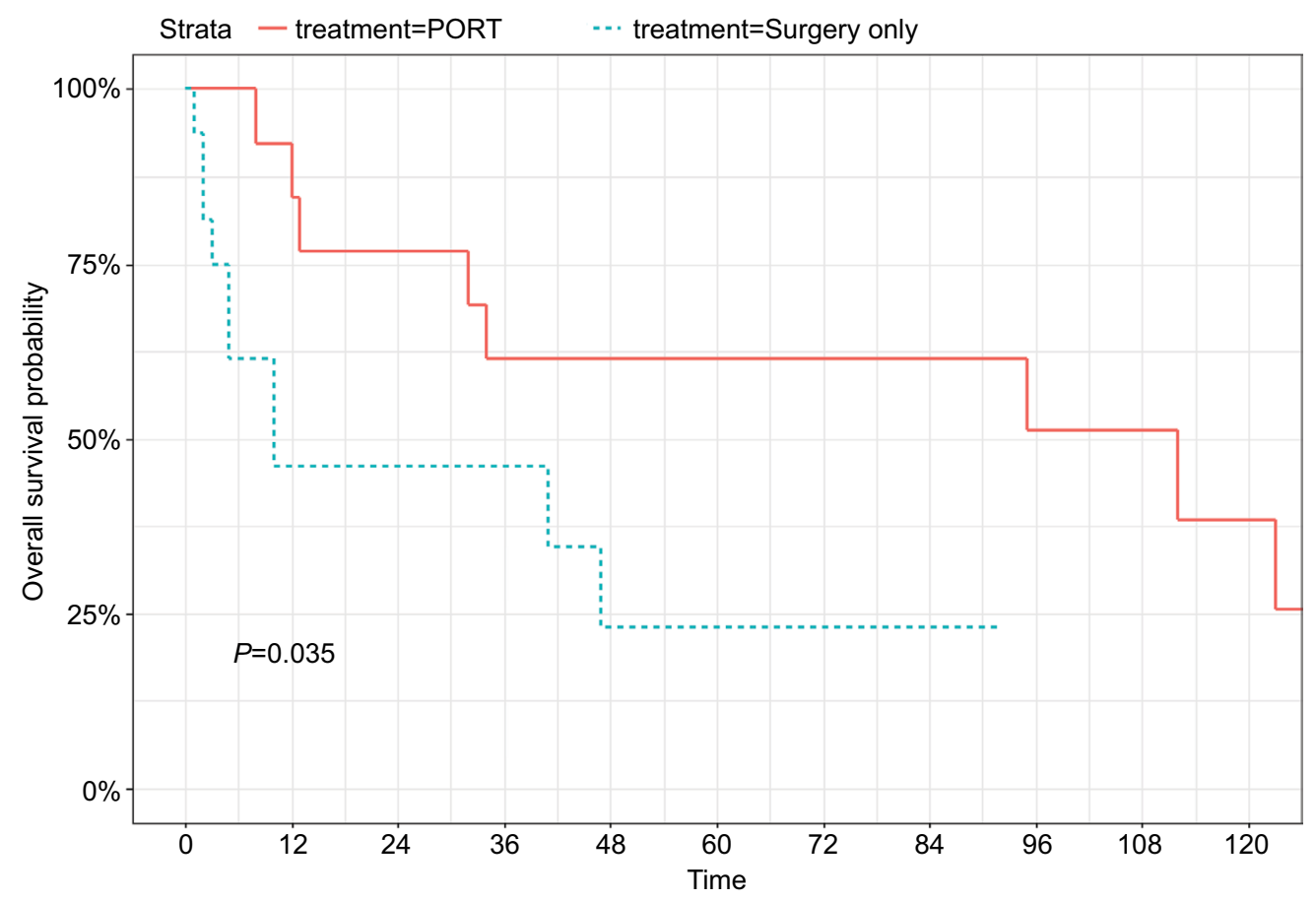

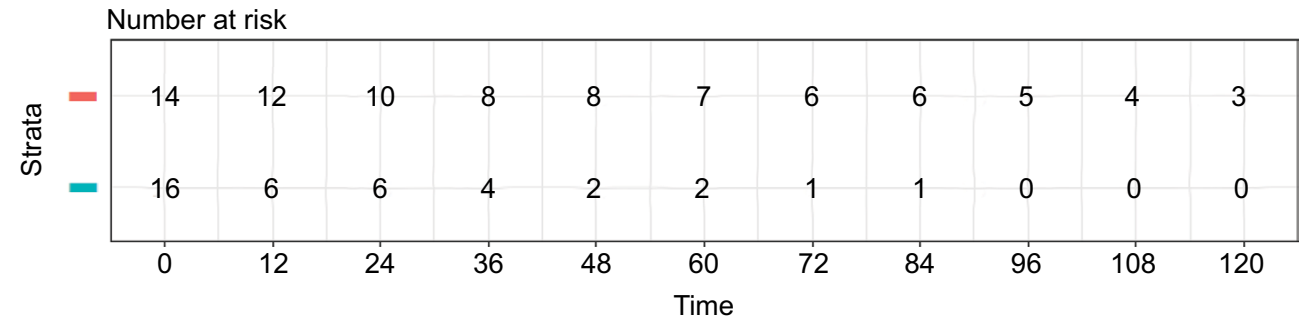

Figure SI OS for SCC tracheal patients who underwent PORT or not in the matched cohort.

Abbreviations: OS, overall survival; PORT, postoperative radiotherapy; SCC, squamous cell carcinoma.

Cancer Management and Research

\section{Publish your work in this journal}

Cancer Management and Research is an international, peer-reviewed open access journal focusing on cancer research and the optimal use of preventative and integrated treatment interventions to achieve improved outcomes, enhanced survival and quality of life for the cancer patient. The manuscript management system is completely online and includes
Dovepress

a very quick and fair peer-review system, which is all easy to use. Visit http://www.dovepress.com/testimonials.php to read real quotes from published authors. 